\title{
Regarding: Analysis of Scoliosis Research Society (SRS) podium presentations for the last seven years: implications of an SRS Annual Meeting Abstract Registry. Cho W, Kim D, Chen F, Moon S, Chang DG. Spine Deform. 2019 Nov; 7(6):845-856. doi:10.1016/j. jspd.2019.04.007. PMID: 31731993
}

\author{
Nathan H. Lebwohl ${ }^{1}$ (B) \\ Received: 25 December 2019 / Accepted: 27 December 2019 / Published online: 5 February 2020 \\ (c) Scoliosis Research Society 2020
}

To the Editor,

I am writing with regard to Dr. Woojin Cho et al.'s paper in the November issue of Spine Deformity 7(2019) 845-856. In it, the authors propose that it would be useful to have an SRS Annual Meeting abstract registry. They created a database consisting of the published abstracts from 2011 to 2017, for the purpose of studying trends in scientific presentations at the SRS Annual Meeting. They state that, to their knowledge, this was "the first attempt to create an abstract registry in the field of orthopedics."

I fully agree with the author's belief that a searchable database of scientific abstracts is a useful tool, similar to PubMed, ScienceDirect, and other research databases of published literature that have become invaluable in the everyday conduct of scientific investigation. As the authors state, a large proportion of podium presentations never lead to publication. Without a searchable database, these research findings may ultimately be lost, especially to younger investigators who are too young to have attended those past meetings.

In recognition of this, in 2005, the Historical Committee of the SRS created a searchable database of Annual Meeting abstracts from 1967 to 2003, which was distributed on CD to all members of the SRS. Since that time, the database has been updated annually, and is currently available to SRS members in the Historical Section of the Society website. It is my hope that this letter will create greater awareness of this invaluable tool.

Sincerely, Nathan H. Lebwohl M.D.

Publisher's Note Springer Nature remains neutral with regard to jurisdictional claims in published maps and institutional affiliations.
Nathan H. Lebwohl

nlebwohl@miami.edu

1 Department of Orthopaedics, University of Miami, Miller School of Medicine, Miami, USA 